\title{
A Solidification Model for Atomization
}

\author{
Arvind PRASAD, ${ }^{1)}$ Salem MOSBAH ${ }^{21}$ Hani HENEIN ${ }^{11}$ and Charles-André GANDIN ${ }^{21}$ \\ 1) Department of Chemical and Materials Engineering, University of Alberta, Edmonton, Alberta, T6G 2 G6 Canada. \\ E-mail: Hani.Henein@ualberta.ca $\quad$ 2) MINES ParisTech, Centre de Mise en Forme des Matériaux, CNRS UMR 7635, BP \\ 207, 06904 Sophia Antipolis, France. E-mail: Charles-Andre.Gandin@mines-paristech.fr
}

(Received on December 3, 2008; accepted on March 2, 2009)

\begin{abstract}
A microsegregation solidification model has been extended for an individual droplet falling through a stagnant gas during the atomization process. Assuming a uniform temperature within the droplet, the model takes into account nucleation undercooling and equiaxed growth of the dendritic and eutectic microstructures until complete solidification. ${ }^{1)}$ It predicts the temperature evolution and the chemical segregation within the droplet in terms of the percent of the dendritic and eutectic microstructures. Extensive experiments have been performed on Al-Cu droplets using the impulse atomization technique. The distribution of phases, cell spacing and segregation have been quantified earlier. ${ }^{2-4)}$ It has been reported that the amount of eutectic in the droplets falls below the equilibrium prediction as the alloy composition increases. Successful comparison between the model results and the experiments leads to the conclusion that eutectic undercooling and eutectic recalescence play a very important role in the final percent of eutectic in the droplets.
\end{abstract}

KEY WORDS: solidification; segregation; atomization.

\section{Introduction}

With Pol Duwez' discovery of the metallurgical benefits of rapid solidification techniques, ${ }^{5)}$ the focus shifted towards developing processes that would yield products offering the benefits of rapid solidification. Rapidly solidified powders are one of the most popular products. They are commonly produced using atomization techniques and have the same microstructural features as that of rapidly solidified materials, ${ }^{6,7)}$ with finer microstructures ${ }^{8-12)}$ and extended solute solubility in their primary phase. ${ }^{13)}$ To attain a desired property from an atomized alloy powder, the microstructure and the weight percent of phases in the powder have to be controlled. To be able to attain this goal, an understanding of the microstructure evolution in the droplets during solidification is important. This requires a formalism of microsegregation of the growing microstructure based on mass balances at the interface between the solid and liquid phases. ${ }^{14)}$

Post-solidification quantitative characterization of powders has been extensively reported in the literature using cell-spacing and dendrite arm measurements as a function of cooling rate. The cooling rates are usually estimated from empirical relationships with cell-spacing. There has been little work done on microsegregation in the atomized powders. Lavernia et al. have studied microsegregation on $\mathrm{Al}-\mathrm{Ti},{ }^{7)} \mathrm{Pd}-\mathrm{Rh}^{12}$ and $\mathrm{Al}-\mathrm{Mn}^{13)}$ gas atomized powders in the size range of less than $100 \mu \mathrm{m}$ diameters only. They have reported $\mathrm{Mn}$ enriched primary $\mathrm{Al}$ in droplet sizes in the range of $100 \mu \mathrm{m}$. The $\mathrm{Al}-\mathrm{Ti}$ and $\mathrm{Pd}-\mathrm{Rh}$ droplet microstructures were studied and explained in terms of solidi- fication growth fronts. More recently, using 2D microscopic examinations, Trivedi et al. ${ }^{15)}$ have studied microstructure and microsegregation in gas atomized Al-Si droplets. They have reported different length-scales of microstructure arising from recalescence in the droplets. They also measured the volume fraction of the different length scales of microstructure in different sections of a droplet of a given size. Prasad et $a l^{2,3)}$ also recently reported quantitative measurements from micro-tomography images. Although important, these studies do not provide a complete picture of the microsegregation phenomena in atomized droplets. Extensive research on the effects of different gas types, and composition for a range of droplet sizes on the distribution of the microstructures has not been performed before. As such the phenomena controlling microstructures in droplets produced under a wide range of operating conditions have not been studied.

Recently, we have conducted extensive research on microsegregation on impulse atomized $\mathrm{Al}-\mathrm{Cu}$ system. The experimental results have already been published. ${ }^{3,4)}$ It was found that the alloy composition has a more significant effect on the final fraction of phases present than cooling rate. To understand the factors influencing microsegregation, a droplet solidification model has been extended to atomization. ${ }^{1)}$ The model takes into account all relevant parameters including primary undercooling, eutectic undercooling, solid state diffusion etc. The following paper describes the model and its results. These results are discussed and conclusions derived about the factors that affect microsegregation in atomized droplets. 


\section{The Impulse Atomization Process}

Impulse Atomization (IA) is a single-fluid atomization process developed at the Advanced Material and Processing Laboratory, University of Alberta, Canada. It consists of a cylindrical chamber that is $4 \mathrm{~m}$ tall and $0.5 \mathrm{~m}$ in diameter. The entire chamber is atmospherically sealed and can be filled with the gas of choice. Typically, an inert gas, $\mathrm{He}, \mathrm{N}_{2}$ or Ar, is used for the atomization experiments. The top portion of the chamber consists of the impulse unit where the material is melted and subsequently pushed through small orifices. The ensuing discontinuous melt streams break down into small droplets that fall through the quiescent gas in the chamber. More details of this process have been described in previous publications. ${ }^{16-18)}$

Briefly, as the liquid droplets fall, the gas in the atomizing chamber extracts the heat from the droplets by convection, whereby the droplets cool and solidify. Since the atomization temperature of $\mathrm{Al}-\mathrm{Cu}$ system is close to $1100 \mathrm{~K}$, the liquid droplets may lose heat to radiation as well. However, since the droplets cool rapidly, the radiation heat loss component decreases drastically, and therefore, has a small effect on the total heat loss. Since the gas is stagnant, the primary function of the gas is to withdraw the heat from the liquid droplets, although the surface tension between the gas and liquid metal does play a part in breaking the liquid stream into droplets. The droplets completely solidify as they fall through $3.5 \mathrm{~m}$ of the gas filled chamber and are collected in glass beakers filled with oil.

It has been shown in previous works ${ }^{10,16)}$ that IA can produce rapidly solidified droplets and that this technique is a useful tool for studying the rapid solidification process. The secondary dendrite arm spacing and cooling rates are often related by an empirical relation of the type $\lambda=A \dot{T}^{-n}$, where $\lambda$ is the dendrite arm spacing and $\dot{T}$ is the cooling rate. ${ }^{19)}$ Wiskel et al. ${ }^{10)}$ have shown that the cooling rate of $\mathrm{Al}-$ $4.5 \mathrm{wt} \% \mathrm{Cu}$ atomized in $\mathrm{He}$ varies for droplets of 950 to $275 \mu \mathrm{m}$ from 325 to $2400 \mathrm{~K} \mathrm{~s}^{-1}$, respectively. On the other hand, the same range of droplets sizes atomized under $\mathrm{N}_{2}$ show cooling rates from 150 to $800 \mathrm{~K} \mathrm{~s}^{-1}$, respectively. Be- cause of the better conductivity of He gas compared to $\mathrm{N}_{2}$, the cooling rate is faster for droplets atomized in $\mathrm{He}$ as compared to $\mathrm{N}_{2}$. Thus, a droplet of a given size in He shows a finer structure compared to the same droplet size atomized in $\mathrm{N}_{2}$. The data also shows that the cell spacing decreases as the droplet size decreases, since smaller droplets cool at a faster rate. The cooling rate values show that the IA can produce rapidly solidified powders.

\section{Experiments}

The rapid solidification experiments using IA were carried out on $\mathrm{Al}-\mathrm{Cu}$ system. Four different $\mathrm{Cu}$ compositions were chosen, i.e. $4.3 \mathrm{wt} \% \mathrm{Cu}, 5 \mathrm{wt} \% \mathrm{Cu}, 10 \mathrm{wt} \% \mathrm{Cu}$ and $17 \mathrm{wt} \% \mathrm{Cu}$. These four alloys were atomized under He and $\mathrm{N}_{2}$ gas. Each atomization run was performed with a nozzle plate containing 37 holes of $250 \mu \mathrm{m}$ diameter each. Different sizes of powders from each run were obtained. The powders from each of these runs were thus sieved. Characterization using X-Ray tomography and scanning electron microscopy (SEM) were then conducted. Table 1 gives the details of the powder description and the characterization employed. ${ }^{18)}$. The details of these techniques are provided elsewhere. ${ }^{2,3)}$ Some of the results from the characterization work are given next.

\subsection{Tomography}

Tomography, conducted at the European Synchrotron Radiation Facility (Grenoble, France), provided the microstructure information for the entire droplet volume. ${ }^{3)}$ The results showed a single nucleation site and anisotropy in the length scale of the microstructure. There were three distinct scales of microstructures evident from the images and appeared to have originated from a single region. A tiny region could be identified as the location where nucleation took place. Surrounding the region containing the nucleation site was a region of very fine structure named the ultra-fine structure. It is believed to be formed during the initial growth regime immediately after nucleation and before the onset of recalescence. The volume percent of this

Table 1. Summary of atomized alloys and the atomization run conditions used in tomography, neutron diffraction (ND) and stereology experiments. ${ }^{18}$

\begin{tabular}{|c|c|c|c|c|c|}
\hline $\begin{array}{c}\text { Droplet } \\
\text { description }\end{array}$ & $\begin{array}{c}\text { Atomization } \\
\text { Gas / Temp. }\end{array}$ & $\begin{array}{c}\text { Actual alloy } \\
\text { comp. }(\mathrm{wt} \%)\end{array}$ & $\begin{array}{c}\text { Average droplet } \\
\text { size }(\mu \mathrm{m})\end{array}$ & $\begin{array}{c}\text { \# of } \\
\text { images }\end{array}$ & $\begin{array}{c}\text { \# of grid } \\
\text { points/image }\end{array}$ \\
\hline $5 / \mathrm{He} / 196 \mu \mathrm{m}$ & $\mathrm{He} / 1123 \mathrm{~K}$ & 4.98 & 196 & 31 & 156 \\
\hline $5 / \mathrm{He} / 925 \mu \mathrm{m}$ & $\mathrm{He} / 1123 \mathrm{~K}$ & 4.98 & 925 & 31 & 156 \\
\hline $5 / \mathrm{N}_{2} / 196 \mu \mathrm{m}$ & $\mathrm{N}_{2} / 1123 \mathrm{~K}$ & 4.92 & 196 & 31 & 156 \\
\hline $5 / \mathrm{N}_{2} / 925 \mu \mathrm{m}$ & $\mathrm{N}_{2} / 1123 \mathrm{~K}$ & 4.92 & 925 & 31 & 154 \\
\hline $10 / \mathrm{He} / 196 \mu \mathrm{m}$ & $\mathrm{He} / 1123 \mathrm{~K}$ & 10 & 196 & 31 & 156 \\
\hline $10 / \mathrm{He} / 925 \mu \mathrm{m}$ & $\mathrm{He} / 1123 \mathrm{~K}$ & 10 & 925 & 39 & 164 \\
\hline $10 / \mathrm{N}_{2} / 234 \mu \mathrm{m}$ & $\mathrm{N}_{2} / 1123 \mathrm{~K}$ & 9.96 & 234 & 31 & 161 \\
\hline $10 / \mathrm{N}_{2} / 925 \mu \mathrm{m}$ & $\mathrm{N}_{2} / 1123 \mathrm{~K}$ & 9.96 & 925 & 40 & 164 \\
\hline $17 / \mathrm{He}_{1} / 196 \mu \mathrm{m}$ & $\mathrm{He} / 1123 \mathrm{~K}$ & 16.8 & 196 & 34 & 157 \\
\hline $17 / \mathrm{He} / 925 \mu \mathrm{m}$ & $\mathrm{He} / 1123 \mathrm{~K}$ & 16.8 & 925 & 30 & 160 \\
\hline $17 / \mathrm{N}_{2} / 234 \mu \mathrm{m}$ & $\mathrm{N}_{2} / 1123 \mathrm{~K}$ & 16.8 & 234 & 31 & 159 \\
\hline $17 / \mathrm{N}_{2} / 780 \mu \mathrm{m}$ & $\mathrm{N}_{2} / 1123 \mathrm{~K}$ & 16.8 & 780 & 31 & 159 \\
\hline
\end{tabular}


initial growth regime in $\mathrm{Al}-4.3 \mathrm{wt} \% \mathrm{Cu}$ and $\mathrm{Al}-17 \mathrm{wt} \% \mathrm{Cu}$ droplets was estimated using stereology. Porosity measurements have also been made on the tomography images, but the porosity results have not been considered for modeling purposes.

\subsection{Microsegregation}

Microsegregation within the droplets was quantified by measuring the amount of eutectic in the droplets of a given chemistry, size and atomized under a given gas type. Eutectic was measured by two different techniques. The first technique was neutron diffraction whereas the second technique was based on stereology applied to microstructural images obtained by electron microscopy. The stereological technique gives the volume percent of eutectic in the droplets. The volume percent eutectic values were converted to weight percent eutectic using mass and volume balance on neutron diffraction results of weight percent of the $\mathrm{Al}_{2} \mathrm{Cu}$ phase and volume percent eutectic. The mathematical formulation has been published in an earlier work, together with the converted weight percent eutectic results. ${ }^{4)}$

\subsection{Cell Spacing}

The same sets of droplets were analyzed for cell spacing using line intercept technique on images obtained from electron microscopes. The results have been published elsewhere ${ }^{2,3)}$ and show that the structure gets finer as the alloy composition is increased. Furthermore, the smaller droplets show a finer structure as does the droplets atomized under He gas.

Because both the microstructure spacing and the percent of phases show dependence with alloy composition, a droplet solidification model was developed based on an extention of a microsegregation model. ${ }^{1)}$ The following describes the model, its predictions and the comparisons between the experimental results.

\section{Model Development}

Most droplet solidification models have been developed for gas atomization, for example Yang et al. ${ }^{12)}$ or Levi and Mehrabian. ${ }^{20)}$ These models have been developed mainly to simulate the cooling rates of the solidifying droplets and solidification growth front velocities but not for predicting microsegregation in terms of the eutectic percent and/or the solute content of the primary phase. In the present contribution, a solidification model is developed for the atomization of a single droplet. It is based on a solution of the thermal energy balance equation as well as the mass transfer equations during the phase transformation while taking into account the nucleation undercooling and growth of the microstructure within the droplets. Details of the solidification model itself are presented elsewhere ${ }^{1)}$ and are not given below. To this model is added a tracking procedure with time of the droplet position and velocity as it falls through the atomization chamber. The later permits to evaluate a convective heat transfer coefficient pertinent with the atomization process that is then coupled with the solidification model.

\subsection{Solidification Model}

The model assumes a uniform temperature for the entire droplet. The droplet starts at the atomization temperature and begins to fall with an initial velocity of $0.5 \mathrm{~m} \mathrm{~s}^{-1} .{ }^{17}$ ) While the droplet continues to fall through the quiescent gas, it loses heat mainly through convection. It can be shown that the radiation heat loss has a small effect $(\sim 3.5 \%$ of the total heat loss) and is thus neglected in this model. The convective heat loss is a result of the relative velocity between the droplet velocity and the atomization gas and its model is explained in the next section.

At some user defined temperature, the nucleation of a microstructure is assumed to occur in the droplet center and to develop by radial growth of a spherical zone. At first, a dendritic microstructure is modeled, followed by a eutectic microstructure. Specific growth kinetics is used for each type of microstructure. ${ }^{21,22}$ Since the region delimited by the dendrite tips and the eutectic lamellae constitutes a mushy zone, mass balances are applied to determine the time evolution of the average composition of the dendritic solid and the interdendritic liquid. This diffusion-based microsegregation model is coupled with diffusion in the extradendritic liquid following the model proposed by Wang and Beckermann. ${ }^{23)}$

The phase transformation results in latent heat release proportional to the solidification rate, and the net heat content of the droplet is given by the difference between the latent heat generated and the convective heat loss. The latent heat is released until solidification is complete. Following complete solidification, the droplet cools due to convective heat losses only. The governing equations for the calculation of the droplet trajectory and heat transfer coefficient are described next.

\subsection{Droplet Trajectory}

As the droplet falls through the chamber, the relative velocity between the droplet and the gas changes as a result of the net forces acting on the droplet. The schematic in Fig. 1 shows the different forces acting on the droplet as well as the energy balance in the droplet. Taking into account all the forces (weight, buoyancy and drag), the net force (instantaneous acceleration) on the droplet can be written as, ${ }^{10)}$

$$
\frac{d v}{d t}=\frac{\rho_{p}-\rho_{f}}{\rho_{p}} g-0.75 \frac{\rho_{f}}{\rho_{p}} \frac{C_{d}}{D_{p}} v^{2}
$$

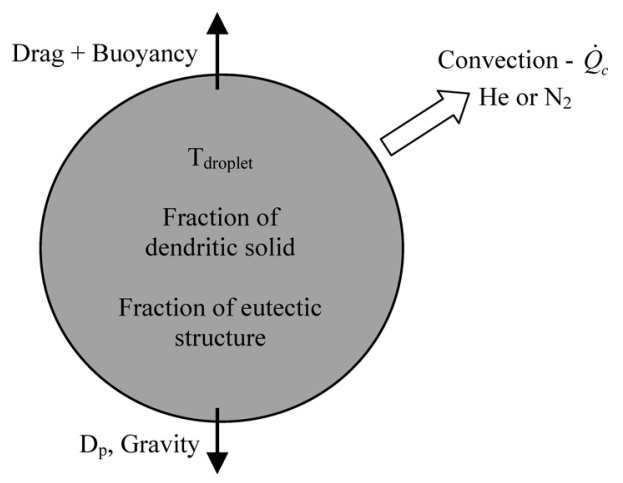

Fig. 1. Schematic of a droplet during atomization with different forces acting on it. 
where $v$ is the relative velocity between the droplet and the atomization fluid; $\rho_{p}$ and $\rho_{f}$ are the densities of the droplet and atomization gas, respectively; $C_{d}$ is the drag coefficient; and $D_{p}$ is the droplet diameter. $C_{d}$ is calculated from ${ }^{24)}$ :

$$
C_{d}=\frac{18.5}{\mathrm{Re}^{0.6}}
$$

The drag coefficient is valid for Reynolds numbers, $\operatorname{Re}=D_{p} \rho_{f} v / \mu_{f}$, in the range of 0.1 to 1000 . By substituting the expression for $C_{d}$ from Eq. (2) and using the definition of Re, Eq. (1) can be rewritten as,

$$
\frac{d v}{d t}=\frac{\rho_{p}-\rho_{f}}{\rho_{p}} g-(18.5 \cdot 0.75) \frac{\rho_{f}^{0.4}}{\rho_{p}} \frac{\mu_{f}^{0.6}}{D_{p}^{1.6}} v^{1.4} \ldots
$$

Equation (3) describes the velocity of the droplet as a function of time as the droplet falls through the atomization chamber. The solution of this equation requires an initial velocity, and this value for the IA process has been established by Ding et al. ${ }^{17)}$

\subsection{Heat Loss from the Droplet}

Convective heat transfer can either be assumed constant (for e.g. Levi et al. ${ }^{20)}$ ) or can be calculated by evaluating the heat transfer coefficient by using empirical correlations. During atomization the relative velocity between the droplet and the atomizing fluid changes constantly; thus the heat transfer coefficient would be a transient value. A constant heat transfer coefficient does not simulate the conditions during an actual atomized droplet cooling process. The Whitaker correlation is used to evaluate the transient heat transfer coefficient during atomization as the gas and the droplet have dramatically different temperatures. ${ }^{10)}$ These expressions help in evaluating the Nusselt number for a sphere of diameter $D_{p}$ placed in the cross-flow of a fluid of thermal conductivity $k_{s}$. Combining this correlation with the definition of Nusselt number, $\mathrm{Nu}=h_{c} D_{p} / k_{s}$, the heat transfer coefficient, $h_{c}$, is evaluated. The mathematical forms of these correlations have Re number, which takes into account the relative velocity between the droplet and the fluid as shown below.

The convective heat loss is calculated using the following expression,

$$
Q_{c}=h_{c}\left(T_{i}-T_{f}\right)
$$

where $h_{c}$ is the convective heat transfer coefficient, $T_{i}$ is the instantaneous droplet temperature and $T_{f}$ is the gas temperature (assumed constant). The droplet temperature is assumed uniform. This is justified by the condition that $\mathrm{Bi}<0.1$, where $\mathrm{Bi}$ is the Biot number. ${ }^{25)}$ The convective heat transfer coefficient, $h_{c}$, is calculated by evaluating the Nusselt number, $\mathrm{Nu}$, which is determined from the modified Whitaker correlation ${ }^{16)}$ as:

$$
\begin{aligned}
\mathrm{Nu}= & \frac{h_{c} D_{p}}{k_{s}}=2\left(\frac{B}{k_{s}(m+1)} \frac{T_{s}^{m+1}-T_{f}^{m+1}}{T_{s}-T_{f}}\right) \\
& +\left(0.4 \mathrm{Re}^{1 / 2}+0.06 \operatorname{Re}^{2 / 3}\right) \operatorname{Pr}^{0.4}\left(\frac{\mu_{\infty}}{\mu_{s}}\right)^{1 / 4}
\end{aligned}
$$

\begin{tabular}{|c|c|c|}
\hline Parameters & & Value \\
\hline Melt temperature $[\mathrm{K}]$ & & 1123 \\
\hline Initial droplet velocity [ms $\left.\mathrm{m}^{-1}\right]$ [17] & & 0.5 \\
\hline Gas temperature $[\mathrm{K}]$ & & 303 \\
\hline Dendritic nucleation undercooling, $\Delta \mathrm{T}_{\mathrm{N}}^{\mathrm{p}}[\mathrm{K}]$ & & 15 \\
\hline Eutectic nucleation undercooling, $\Delta \mathrm{T}_{\mathrm{N}}{ }^{\mathrm{e}}[\mathrm{K}]$ & $\begin{array}{r}5 w t \% C u \\
10 w t \% C u \\
17 w t \% C u\end{array}$ & $\begin{array}{c}20 \\
20 \\
27.5\end{array}$ \\
\hline
\end{tabular}

where $D_{p}$ is the droplet diameter, $k_{s}$ is the gas thermal con-
Table 2. Properties of alloys used in the simulation. ${ }^{26-28)}$

\begin{tabular}{|l|c|c|c|c|}
\hline Alloy properties & $4.3 \% \mathrm{Cu}$ & $5 \% \mathrm{Cu}$ & $10 \% \mathrm{Cu}$ & $17 \% \mathrm{Cu}$ \\
\hline Liquidus temperature $[\mathrm{K}]$ & 922 & 920 & 907 & 885 \\
\hline Density $\left[\mathrm{kg} \mathrm{m}^{-3}\right]$ & 2750 & 2760 & 2870 & 3100 \\
\hline Specific heat $\left[\mathrm{J} \mathrm{K}^{-1} \mathrm{~m}^{-3}\right]$ & $3.2378 \cdot 10^{6}$ & $3.2465 \cdot 10^{6}$ & $3.3087 \cdot 10^{6}$ & $3.3957 \cdot 10^{6}$ \\
\hline Latent heat $\left[\mathrm{J} \mathrm{m}^{-3}\right]$ & $10.8113 \cdot 10^{8}$ & $10.8661 \cdot 10^{8}$ & $11.2575 \cdot 10^{8}$ & $11.8054 \cdot 10^{8}$ \\
\hline Liquidus slope $\left[\mathrm{K}(\%)^{-1}\right]$ & -3.63 & -3.66 & -3.86 & -4.23 \\
\hline Partition coefficient $[-]$ & 0.177 & 0.178 & 0.194 & 0.224 \\
\hline
\end{tabular}

Table 3. Initial values used in the simulations.

ductivity evaluated at the temperature of the droplet surface and $T_{s}$ is the droplet surface temperature, which is replaced by $T_{i}$, based on the assumption of a uniform temperature droplet. $T_{f}$ is the fluid temperature in the bulk assumed to be constant. $\operatorname{Re}$ and $\operatorname{Pr}=\mu_{f} /\left(\rho_{f} \alpha_{f}\right)$ are the Reynolds and Prandtl numbers, respectively. Finally, $\mu_{\infty}$ and $\mu_{s}$ are the viscosity of the fluid in the bulk and on the droplet surface, respectively, evaluated at the temperature of the bulk fluid, $T_{\infty}$, and at the droplet temperature. Since Re is a function of the droplet velocity, once the velocity is known, the heat transfer coefficient can be evaluated using Eq. (5). The convective heat loss is then calculated from Eq. (4). The various material properties ${ }^{26-28)}$ and initial values used in the simulations are given in Tables $\mathbf{2}$ and $\mathbf{3}$ respectively.

\section{Results and Discussion}

\subsection{Droplet Undercooling Analysis}

A summary of the experimental results is provided in Table 4. The experimental results include volume percent eutectic from stereology $\left(\mathrm{v}^{\mathrm{e}}\right)$, weight percent of the $\theta$ $\mathrm{Al}_{2} \mathrm{Cu}$ phase from neutron diffraction $\left(\mathrm{w}^{\theta}\right)$, the converted weight percent eutectic $\left(\mathrm{fs}^{\mathrm{e}}\right)$ from a combination of volume percent eutectic and weight percent $\mathrm{Al}_{2} \mathrm{Cu}$. The average dendrite arm spacing (DAS) is also reported. It is used as the length scale for solid state diffusion in the solidification model. ${ }^{1}$ As the nucleation undercooling of the primary dendritic and secondary eutectic microstructures are also needed as parameters of the model, one has to estimate them.

It was mentioned under the experimental section that the volume percent of initial growth regime in the droplet was estimated using stereology. The model simulation result gives the volume of envelope of the growing mushy zone as a function of the droplet temperature. Hence the volume of the envelope can be ascertained in different regimes, i.e. initial growth, recalescence and post-recalescence. This approach was used to compare the volume percent of solid formed during the initial growth regime prior to recalescence. The model was run for the $\mathrm{Al}-4.3 \mathrm{wt} \% \mathrm{Cu}, 660 \mu \mathrm{m}$ droplet under $\mathrm{N}_{2}$ gas. It was found that increasing the primary nucleation undercooling resulted in a decrease in the 
volume of the grain envelope formed during the initial growth regime. This is illustrated in Fig. 2 and can be explained as follows. The dendrite growth rate is proportional to the undercooling and the presence of primary nucleation undercooling thus results in some finite growth rates of the dendrites. Following nucleation, the droplet continues to cool and the undercooling increases further. Consequently, the dendrite growth rate increases with a resulting increase in the rate of latent heat generation. At some point, when the latent heat released is greater than the convective heat loss from the droplet, recalescence sets in, wherein the droplet temperature increases while solidification proceeds. At higher initial primary undercooling, the dendrite growth rates are faster and the recalescence sets in faster thereby decreasing the initial growth regime. The experimental result superimposed on the predictions in Fig. 2 shows that there is a match for a primary undercooling of $15 \mathrm{~K}$. Thus, it is believed that the droplet underwent a primary nucleation undercooling evaluated to $15 \mathrm{~K}$ and all further simulations were run with $15 \mathrm{~K}$ of primary undercooling. Although there is no reason for extension of this value to all alloys and droplets, the effect of the primary nucleation un-

Table 4. Summary of experiment results for the atomized droplets using stereology (St.) and neutron diffraction (ND).

\begin{tabular}{|c|c|c|c|c|}
\hline $\begin{array}{c}\text { Droplet } \\
\text { history }\end{array}$ & $\begin{array}{c}\mathrm{v}^{\mathrm{e}}(\%) \\
\text { St. }\end{array}$ & $\begin{array}{c}\mathrm{w}^{\theta}(\%) \\
\mathrm{ND}\end{array}$ & $\begin{array}{c}\mathrm{fs}^{\mathrm{e}}(\%) \\
\text { St.+ND }\end{array}$ & $\begin{array}{c}\text { DAS } \\
(\mu \mathrm{m})\end{array}$ \\
\hline $5 / \mathrm{He} / 196 \mu \mathrm{m}$ & 4.63 & 4.45 & 6.14 & 2.11 \\
\hline $5 / \mathrm{He} / 925 \mu \mathrm{m}$ & 5.77 & 4.55 & 7.29 & 5.63 \\
\hline $5 / \mathrm{N}_{2} / 196 \mu \mathrm{m}$ & 5.62 & 4.73 & 7.20 & 4.21 \\
\hline $5 / \mathrm{N}_{2} / 925 \mu \mathrm{m}$ & 5.34 & 4.71 & 6.92 & 7.07 \\
\hline $10 / \mathrm{He} / 196 \mu \mathrm{m}$ & 12.52 & 9.3 & 15.41 & 2.21 \\
\hline $10 / \mathrm{He} / 925 \mu \mathrm{m}$ & 13.75 & 9.2 & 16.57 & 4.62 \\
\hline $10 / \mathrm{N}_{2} / 234 \mu \mathrm{m}$ & 13.08 & 11.8 & 16.72 & 3.56 \\
\hline $10 / \mathrm{N}_{2} / 925 \mu \mathrm{m}$ & 14.62 & 9.98 & 17.64 & 5.93 \\
\hline $17 / \mathrm{He} / 196 \mu \mathrm{m}$ & 28.1 & 17.5 & 32.57 & 1.41 \\
\hline $17 / \mathrm{He} / 925 \mu \mathrm{m}$ & 27.0 & 18.13 & 31.70 & 3.16 \\
\hline $17 / \mathrm{N}_{2} / 234 \mu \mathrm{m}$ & 26.08 & 18.43 & 30.91 & 2.49 \\
\hline $17 / \mathrm{N}_{2} / 780 \mu \mathrm{m}$ & 30.03 & 18.45 & 34.61 & 4.46 \\
\hline
\end{tabular}

dercooling of the dendritic microstructure will later be shown as not being critical for the present study, thus justifying this approximation.

The nucleation undercooling of the eutectic microstructure was estimated based on the experimental measurements reported by Gandin et al. ${ }^{1)}$ These authors measured the time evolution of the temperature of levitated $\mathrm{Al}-\mathrm{Cu}$ droplets of compositions $4 \mathrm{wt} \% \mathrm{Cu}, 14 \mathrm{wt} \% \mathrm{Cu}$ and $24 \mathrm{wt} \%$ $\mathrm{Cu}$. They found an increase of the nucleation undercooling of the eutectic microstructure with increasing alloy composition. Interpolation through these data was made and lead to the nucleation undercooling reported in Table 3.

\subsection{Effect of Non-isothermal Eutectic Transforma- tions}

In Table 5, the simulation results include weight percent eutectic, $\mathrm{fs}^{\mathrm{e}}$, for two different sets of simulations. The conditions for the simulations are the same: user defined primary and eutectic undercooling and zero or non-zero solid state diffusion. Under this condition, $2 \mathrm{wt} \%$ eutectic are reported-one for eutectic with non-isothermal transformation, columns labeled $\mathrm{fs}^{\mathrm{e}}$ in Table 5, and the other with isothermal transformation, columns labeled $\mathrm{fs}^{\mathrm{e}}\left(\Delta \mathrm{T}_{\mathrm{N}}^{\mathrm{e}}\right)$ in Table 5. Cooling rates are estimated from the predicted thermal history of the droplet simulations and also reported in Table 5.

In the case of isothermal transformations, $\mathrm{fs}^{\mathrm{e}}\left(\Delta \mathrm{T}_{\mathrm{N}}^{\mathrm{e}}\right)$, the predicted weight percent of eutectic is systematically larger than when the temperature is not fixed, $\mathrm{fs}^{\mathrm{e}}$. In fact, in case of an isothermal transformation, the remaining liquid at temperature $T_{E}-\Delta T_{N}^{e}$ is simply transformed into eutectic. In the case of non-isothermal transformation, the temperature is free to decrease and/or to increase as the result of the eutectic growth and latent heat release, nucleation being set at the same temperature, $\mathrm{T}_{\mathrm{E}}-\Delta \mathrm{T}_{\mathrm{N}}^{\mathrm{e}}$. As a result, some primary dendritic solid continues to form below the nucleation temperature chosen for the eutectic microstructure and the remaining liquid transforming into eutectic is consequently less.

\subsection{Effect of Solid State Diffusion and Primary Den- dritic Nucleation Undercooling}

The role of diffusion in the primary dendritic solid is shown by comparison of columns 3 and 4 with columns 5 and 6 , respectively in Table 5 . Very little difference is seen

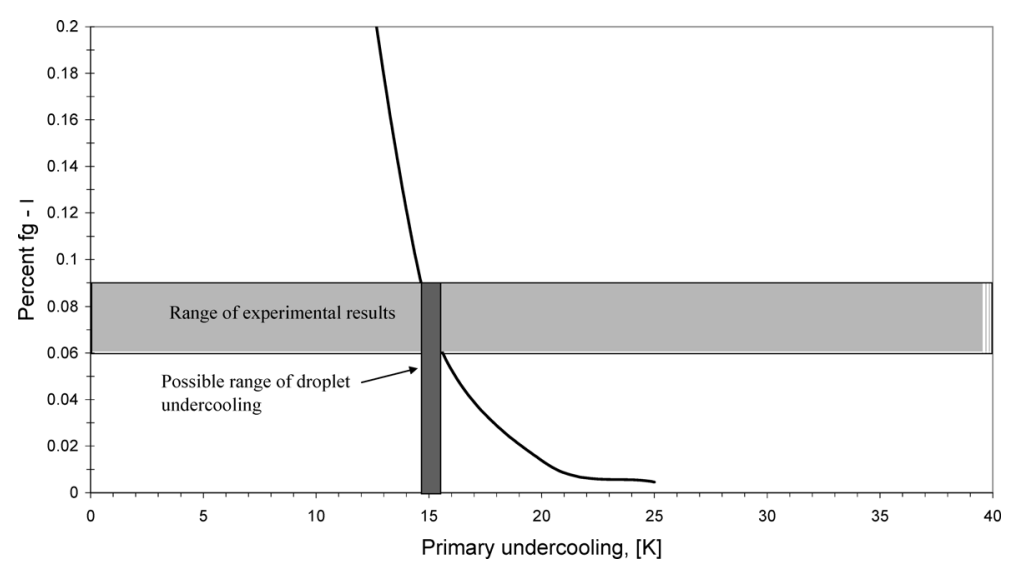

Fig. 2. Comparison between experimental and model results for volume percent of Region $\mathrm{I}$ in the $\mathrm{Al}-4.3 \mathrm{wt} \% \mathrm{Cu}$ $660 \mu \mathrm{m}$ droplet atomized in $\mathrm{N}_{2}$. 
Table 5. Predicted effects of solid diffusion in the primary dendritic structure and nucleation undercooling on the final weight percent of the eutectic structure.

\begin{tabular}{|c|c|c|c|c|c|c|c|c|c|}
\hline \multirow{3}{*}{ Droplet \# } & \multirow{3}{*}{$\begin{array}{c}\text { Cooling } \\
\text { Rate } \\
\left(\mathrm{K} \mathrm{s}^{-1}\right)\end{array}$} & \multirow{2}{*}{\multicolumn{2}{|c|}{$\begin{array}{l}\mathrm{D}^{\mathrm{s}}=0 \mathrm{~m}^{2} \mathrm{~s}^{-1} \\
\Delta \mathrm{T}_{\mathrm{N}}^{\mathrm{p}}=0 \mathrm{~K} \\
\Delta \mathrm{T}_{\mathrm{N}}^{\mathrm{e}}=0 \mathrm{~K}\end{array}$}} & \multicolumn{6}{|c|}{$\mathrm{D}^{\mathrm{s}} \neq 0 \mathrm{~m}^{2} \mathrm{~s}^{-1}$} \\
\hline & & & & \multicolumn{2}{|c|}{$\begin{array}{l}\Delta \mathrm{T}_{\mathrm{N}}^{\mathrm{p}}=0 \mathrm{~K} \\
\Delta \mathrm{T}_{\mathrm{N}}{ }^{\mathrm{e}}=0 \mathrm{~K}\end{array}$} & \multicolumn{2}{|c|}{$\begin{array}{c}\Delta \mathrm{T}_{\mathrm{N}}^{\mathrm{p}}=15 \mathrm{~K} \\
\Delta \mathrm{T}_{\mathrm{N}}{ }^{\mathrm{e}}=0 \mathrm{~K}\end{array}$} & \multicolumn{2}{|c|}{$\begin{array}{c}\Delta \mathrm{T}_{\mathrm{N}}^{\mathrm{p}}=15 \mathrm{~K} \\
\Delta \mathrm{T}_{\mathrm{N}}{ }^{\mathrm{e}} \neq 0 \mathrm{~K}\end{array}$} \\
\hline & & $\mathrm{fs}^{\mathrm{e}}\left(\Delta \mathrm{T}_{\mathrm{N}}{ }^{\mathrm{e}}\right)$ & $\mathrm{fs}^{\mathrm{e}}$ & $\mathrm{fs}^{\mathrm{e}}\left(\Delta \mathrm{T}_{\mathrm{N}}^{\mathrm{e}}\right)$ & $\mathrm{fs}^{\mathrm{e}}$ & $\mathrm{fs}^{\mathrm{e}}\left(\Delta \mathrm{T}_{\mathrm{N}}{ }^{\mathrm{e}}\right)$ & $\mathrm{fs}^{\mathrm{e}}$ & $\mathrm{fs}^{\mathrm{e}}\left(\Delta \mathrm{T}_{\mathrm{N}}{ }^{\mathrm{e}}\right)$ & $\mathrm{fs}^{\mathrm{e}}$ \\
\hline $5 / \mathrm{He} / 196 \mu \mathrm{m}$ & 4689 & 9.95 & 5.78 & 9.87 & 5.82 & 9.87 & 5.84 & 8.18 & 5.73 \\
\hline $5 / \mathrm{He} / 925 \mu \mathrm{m}$ & 349 & 9.89 & 6.93 & 9.73 & 6.76 & 9.73 & 6.75 & 8.06 & 6.67 \\
\hline $5 / \mathrm{N}_{2} / 196 \mu \mathrm{m}$ & 973 & 10.18 & 6.85 & 10.10 & 6.83 & 10.09 & 6.82 & 8.23 & 8.23 \\
\hline $5 / \mathrm{N}_{2} / 925 \mu \mathrm{m}$ & 153 & 9.97 & 7.51 & 9.74 & 7.29 & 9.73 & 7.29 & 8.06 & 7.15 \\
\hline $10 / \mathrm{He} / 196 \mu \mathrm{m}$ & 3546 & 22.34 & 14.73 & 22.30 & 14.68 & 22.29 & 14.68 & 18.63 & 14.58 \\
\hline $10 / \mathrm{He} / 925 \mu \mathrm{m}$ & 258 & 22.37 & 17.35 & 22.19 & 17.14 & 22.19 & 17.13 & 18.51 & 16.95 \\
\hline $10 / \mathrm{N}_{2} / 234 \mu \mathrm{m}$ & 608 & 22.77 & 17.48 & 22.65 & 17.34 & 22.65 & 17.34 & 18.90 & 17.05 \\
\hline $10 / \mathrm{N}_{2} / 925 \mu \mathrm{m}$ & 113 & 22.53 & 17.59 & 22.26 & 17.10 & 22.26 & 17.76 & 18.56 & 18.24 \\
\hline $17 / \mathrm{He} / 196 \mu \mathrm{m}$ & 2258 & 41.51 & 30.88 & 41.48 & 30.79 & 41.48 & 30.78 & 32.94 & 30.36 \\
\hline $17 / \mathrm{He} / 925 \mu \mathrm{m}$ & 176 & 41.76 & 35.04 & 41.59 & 34.68 & 41.59 & 34.68 & 32.95 & 34.11 \\
\hline $17 / \mathrm{N}_{2} / 234 \mu \mathrm{m}$ & 433 & 42.25 & 31.36 & 42.13 & 32.33 & 42.13 & 35.97 & 33.43 & 35.31 \\
\hline $17 / \mathrm{N}_{2} / 780 \mu \mathrm{m}$ & 97 & 42.03 & 37.19 & 41.83 & 36.82 & 41.83 & 36.82 & 33.15 & 36.10 \\
\hline
\end{tabular}

between the predicted weight percent eutectic. This is due to the high cooling rates achieved, not permitting solid state diffusion to play a major role despite the small dendrite arm spacing (Table 4).

The effect of adding the primary dendritic nucleation undercooling is shown by comparison of columns 5 and 6 with columns 7 and 8 in Table 5. Again, very little difference is seen between the predicted weight percent eutectic. Additional calculations were run by progressively increasing the primary nucleation undercooling up to $40 \mathrm{~K}$. A negligible effect was found, which is in agreement with previous exploitation of the model. ${ }^{1)}$ A comparison has been made between the current atomization results and recently published drop-tube experimental results of Kasperovich et al. ${ }^{29)}$ The amount of eutectic reported by Kasperovich et al. for $\mathrm{Al}-4 \mathrm{wt} \% \mathrm{Cu}$ droplets are: $\mathrm{fs} \approx 1 \%$ for $916 \mu \mathrm{m}$ droplet in He (cooling rate $=310 \mathrm{~K} / \mathrm{s}$ ) and $\mathrm{fs} \approx 0.6 \%$ for a $209 \mu \mathrm{m}$ droplet in He (cooling rate $=4300 \mathrm{~K} / \mathrm{s}$ ). The amount of eutectic reported for the corresponding atomized droplets for Al- $-5 \mathrm{wt} \% \mathrm{Cu}$ (Table 4) are $\mathrm{fs} \mathrm{e}^{\mathrm{e}} \approx 7 \%$ and $\mathrm{fs} \mathrm{e}^{\mathrm{e}} \approx 6 \%$ respectively. The cooling rates for the atomized droplets (Table 5) are comparable with the drop-tube droplets. This is due to the fact that the heat transfer mechanism in drop-tube and in impulse atomization processes are principally the same. In light of this, the fraction eutectic values from drop-tube experiments are much lower compared to the impulse atomized droplets. Heringer et $a l .{ }^{30)}$ have demonstrated the presence of macrosegregation in atomized $\mathrm{Al}-10 \mathrm{wt} \% \mathrm{Cu}$ samples. Thus a 3D quantification technique is necessary to get the global eutectic fraction from the entire droplet volume. Kasperovich et al. have performed stereological analysis on 2D sections of the drop-tube droplets to estimate the eutectic fraction. Thus, one possible explanation of such low eutectic fraction is the presence of macrosegregation in the drop-tube samples which has not been adequately captured by the $2 \mathrm{D}$ analysis. Note that Prasad et al. performed neu- tron diffraction experiments ${ }^{4)}$ on atomized droplets to capture the volume information of segregation in the droplets.

Another possibility for such reduction in segregation can be due to solute trapping in the drop-tube droplets, thus significantly reducing the amount of the second phase. Solute trapping can result from very high primary phase nucleation undercooling. High primary phase undercooling may occur in drop-tube facilities ${ }^{31)}$ and primary undercooling in drop tubes are often estimated from heat transfer calculations. For instance, an undercooling of $150 \mathrm{~K}$ was estimated in $\mathrm{Al}-\mathrm{Mn}$ droplets, compared to $15 \mathrm{~K}$ undercooling estimated for the atomized droplets. At such high undercooling solute trapping may indeed be operative. However, to estimate the undercooling in drop tubes, the Ranz-Marshall convective heat transfer coefficient was used in the calculation. ${ }^{31,32)}$ It has been clearly shown by Wiskel et al. ${ }^{10)}$ that Ranz-Marshall coefficient is not valid and that a modified Whitaker correlation needs to be used. This difference in the heat transfer coefficient can change the estimated undercooling. Hence it is not clear if the $150 \mathrm{~K}$ undercooling is an accurate estimate for drop tube experiments.

Figure 3 gathers all simulation results of Table 5 column $7\left(\mathrm{D}^{\mathrm{s}} \neq 0 \mathrm{~m}^{2} \mathrm{~s}^{-1}, \Delta \mathrm{T}_{\mathrm{N}}^{\mathrm{p}}=15 \mathrm{~K}, \Delta \mathrm{T}_{\mathrm{N}}^{\mathrm{e}}=0 \mathrm{~K}\right)$. Simulations using the Scheil and lever-rule (equilibrium) microsegregation approximations are also shown as dashed lines. As can be seen, the predictions of the model (crosses) are almost superimposed with the Scheil approximation, confirming the minor role played by solid state diffusion and the primary nucleation undercooling. Also in Fig. 4 is plotted the evolution of the measured percent eutectic as a function of the cooling rate for $\mathrm{Al}-5 \mathrm{wt} \% \mathrm{Cu}$ droplets. The cooling rate values are the same as reported in Table 5. Again, little variation is observed, confirming little dependency with the cooling rate and hence with diffusion in the primary solid. It is also to be noted that, when transforming the remaining liquid into a eutectic structure assuming an isothermal reac- 


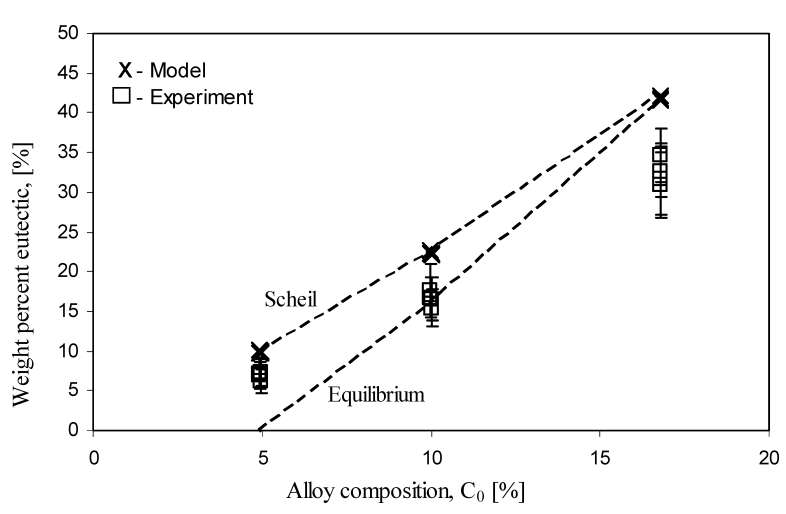

Fig. 3. Figure comparing the weight percent eutectic from experiments and model. The model was run with eutectic assumed to occur at equilibrium under iso-thermal condition.

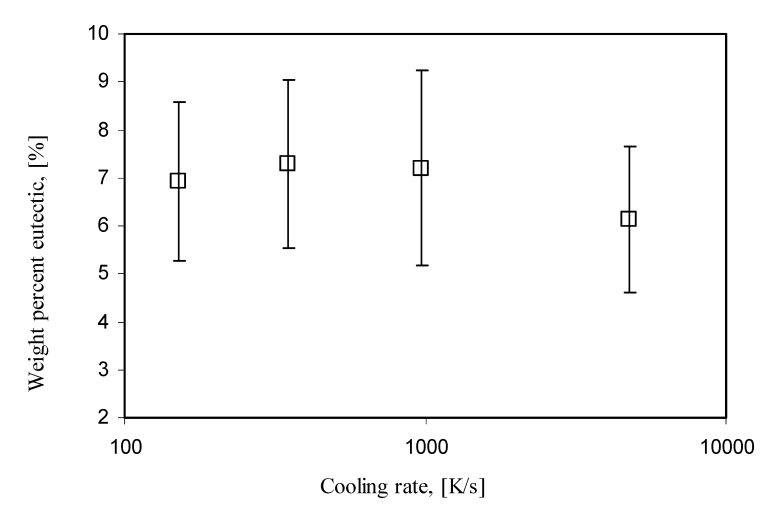

Fig. 4. Effect of cooling rate on the weight percent eutectic for $\mathrm{Al}-5 \mathrm{wt} \% \mathrm{Cu}$ droplets. The cooling rates were evaluated from the model (Table 5).

tion $\left(\mathrm{fs}^{\mathrm{e}}\left(\Delta \mathrm{T}_{\mathrm{N}}^{\mathrm{e}}\right)\right)$, the model predicts less eutectic when permitting diffusion in the solid (compare column 3 with column 5 in Table 5), which is expected from classical microsegregation analyses. ${ }^{14)}$ However, the same effect is not systematically retrieved when adding the nucleation and growth of the eutectic structure (compare column 4 with column 6 in Table 5). The reason is that temperature is no longer fixed upon eutectic reaction and diffusion in the primary solid phase is still computed. Competition occurs between diffusion in the solid phase and eutectic recalescence that mainly depends on the droplet size and processing gas, thus explaining the results.

\subsection{Effect of the Secondary Eutectic Nucleation Un- dercooling}

The prediction results presented so far poorly compare with the experimental results as shown in Fig. 3. Clearly, eutectic undercooling has an important part to play in the final microsegregation since it is the only way to substantially decrease the eutectic percent in the present atomized droplets. Column 9 Table 5 shows the results of simulations considering an isothermal eutectic transformation taking place below the equilibrium temperature, i.e. using the nucleation undercooling for the eutectic microstructure given in Table 3. Comparison with the predictions shown in column 7 Table 5 confirms that the eutectic percent is systematically decreased. As explained above, the dendritic structure can continue to form below the eutectic temperature

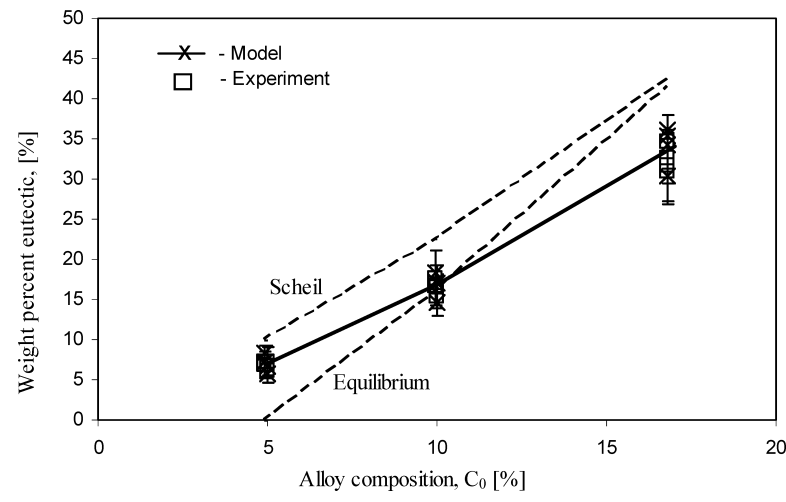

Fig. 5. Comparison of weight percent eutectic between model and experiment. The model was run with estimated eutectic undercooling under non isothermal condition. The line for the model results represents average weight percent eutectic for a given composition.

and thus less liquid is available to grow the eutectic structure at a lower temperature. ${ }^{1)}$ The release of the isothermal transformation approximation upon eutectic growth while keeping the nucleation of the eutectic structure as set by the values in Table 3 leads to the simulation results given in column 10 Table 5. Variations shown by comparison of column 9 Table 5 with column 10 Table 5 depends on the occurrence of a eutectic recalescence. Indeed, a eutectic recalescence leads to partial remelting of the existing primary dendritic structure and an increase of the remaining liquid to be transformed into eutectic. So depending on the alloy composition, cooling rate and eutectic nucleation undercooling, the final weight percent eutectic, $\mathrm{fs}^{\mathrm{e}}$, could be lower or higher compared to the prediction using the isothermal transformation, $\mathrm{fs}^{\mathrm{e}}\left(\Delta \mathrm{T}_{\mathrm{N}}^{\mathrm{e}}\right)$.

Figure 5 shows the predictions using column 10 Table 5. A good agreement is reached with the experimental measurements. It is interesting to once again compare the results recently published by Kasperovich et al. ${ }^{29)}$ They performed levitation and drop-tube experiments (among other solidification techniques) on $\mathrm{Al}-4 \mathrm{wt} \% \mathrm{Cu}$ samples and compared their experimental results with a solidification model based on a direct computation of the dendritic microstructure. An appropriate constant cooling rate (obtained from experimental observation or theoretical calculations) was imposed on the model and no nucleation undercooling or recalescence was considered. The experimental result for levitation experiment by Kasperovich et al. $\left(\mathrm{fs}^{\mathrm{e}}=6.32, \mathrm{dT} / \mathrm{dt}=\right.$ $2.9^{29)}$ ) compares well with the levitation experiment on the same alloy composition conducted by Gandin et al. $\left(\mathrm{fs}^{\mathrm{e}}=\right.$ 5.6, $\left.\mathrm{dT} / \mathrm{dt}=6.5^{1)}\right)$. However, the simulation result from Kasperovich et al. shows $\mathrm{fs}^{\mathrm{e}}=7.5$, which is approximately $20 \%$ more than the experimental result. Gandin et al. ${ }^{1)}$ have analyzed simulation results to study the role of nucleation undercooling (primary as well as eutectic) and solid state diffusion. They show that the presence of non-isothermal eutectic transformation with solid state diffusion yields a much better match between their experimental and the model results. For instance, when no undercooling is considered, their model predicts $\mathrm{fs}^{\mathrm{e}}=6.01$ (experimental $\mathrm{fs}^{\mathrm{e}}=$ 5.6). On the other hand, when nucleation undercooling is considered, the model prediction is $\mathrm{fs}^{\mathrm{e}}=5.62$. This clearly shows the effect of nucleation undercooling of the eutectic 
structure on the final segregation in both levitated as well as atomized droplets.

\section{Conclusions}

In summary, a model was successfully developed to study the solidification of atomized droplets. The present list of achievements and conclusions summarizes the present content of the study performed on atomized $\mathrm{Al}-\mathrm{Cu}$ droplets:

(1) A microsegregation model developed by Gandin et $a l .{ }^{1)}$ has been extended for the study of solidification of individual droplets produced by atomization. The model assumes a uniform temperature droplet.

(2) A method is proposed for the estimation of the nucleation undercooling of the primary dendritic phase. The primary undercooling of the droplets is estimated to be $15 \mathrm{~K}$. The nucleation undercooling of the eutectic structure is deduced from interpolation using previous measurements. ${ }^{1)}$

(3) Other parameters of the model, such as the dendrite arm spacing, is directly measured from the image analyses of the Al-Cu samples.

(4) Comparison between model prediction and experiments is performed considering the eutectic percent.

(5) It is found that a reasonable match between prediction and measurements can only be reached when using a nucleation undercooling for the eutectic structure. Thus the eutectic undercooling and eutectic recalescence play a very important role in the final percent of eutectic in the droplets.

\section{Acknowledgements}

Part of this work was conducted under a grant of the Microgravity Application Promotion program of the European Space Agency (contract \#15236/02/NL/SH). Funding from the Canadian Space Agency and the Natural Sciences and Engineering research Council of Canada is also acknowledged.

\section{REFERENCES}

1) Ch.-A. Gandin, S. Mosbah, Th. Volkmann and D. M. Herlach: Acta Mater., 56 (2008), 3023.

2) A. Prasad, H. Henein, E. Maire and Ch.-A. Gandin: Can. Metall. Q,
43 (2004), 273

3) A. Prasad, H. Henein, E. Maire and Ch.-A. Gandin: Metall. Mater. Trans. A, 37 (2006), 249.

4) A. Prasad, H. Henein and K. T. Conlon: Metall. Mater. Trans. A, 37 (2006), 1589.

5) P. Duwez, R. H. Willens and W. Klement: J. Appl. Phys., 31 (1960), 1136.

6) T. S. Srivatsan and T. S. Sudarshan: Technomic Publishing Company Inc., Pennsylvania, USA, (1993), 127.

7) M. Gupta, F. A. Mohamed and E. J. Lavernia: Scr. Metall. Mater, 26 (1992), 697.

8) O. Grinder and P. Billgren: Powder metallurgy, Pennsylvania, USA, (1994), 903.

9) J. Baram and E. J. Lavernia: J. Mater. Sci. Lett., (1989), 612.

10) J. B. Wiskel, K. Navel, H. Henein and E. Maire: Can. Metall. Q., 41 (2002), 193.

11) N. Tiedje, P. N. Hansen and A. S. Pederson: Metall. Mater. Trans. A, 27 (1996), 4085.

12) N. Yang, S. E. Guthrie, S. Ho and E. J. Lavernia: J. Mater. Sci., 32 (1997), 6589.

13) M. Ruhr, E. J. Lavernia and J. C. Baram: Metall. Trans. A, 21 (1990), 1785 .

14) W. Kurz and D. J. Fisher: Fundamentals of Solidification, Trans Tech Publications, Switzerland, (1989).

15) R. Trivedi, F. Jin and I. E. Anderson: Acta Mater, 51 (2003), 289.

16) J. B. Wiskel, H. Henein and E. Maire: Can. Metall. Q, 41 (2002), 97.

17) Y. Ding: PhD Thesis, University of Alberta, Canada, (1997).

18) A. Prasad: PhD Thesis, University of Alberta, Canada, (2006).

19) H. Jones: Rapid Solidification of Metals and Alloys, The Institution of Metallurgists, London, UK, (1983), 40.

20) C. G. Levi and R. Mehrabian: Metall. Trans. A, 13 (1982), 221.

21) W. Kurz, B. Giovanola and R. Trivedi: Acta Metall., 34 (1986), 823.

22) K. A. Jackson and J. D. Hunt: Trans. Metall. Soc. AIME, 236 (1966), 1129.

23) C. Y. Wang and C. Beckermann: Metall. Trans. A, 24 (1993), 2787.

24) A. J. Yule and J. J. Dunkley: Oxford Series on Advanced Manufacturing, Clarendon Press, Oxford, UK, (1994).

25) W. S. Jana: PWS Engineering, Boston, USA, (1986), 251.

26) Smithells Metals Reference Book, E. A. Brandes and G. B. Brook (eds.), Butterworths-Heinemann, London, UK, (1998).

27) O. Kubaschewski and C. B. Alcock: Metallurgical Thermochemistry, Pergamon Press, New York, USA, (1979), 326.

28) R. I. L. Guthrie: Engineering in Process Metallurgy, Clarendon Press, Oxford, UK, (1992), 484.

29) G. Kasperovich, T. Volkmann, L. Ratke and D. M. Herlach: Metall. Trans. A, 39 (2008), 1183.

30) R. Heringer, Ch.-A. Gandin, G. Lesoult and H. Henein: Acta Mater, 54 (2006), 4427.

31) J. Kreis, D. M. Herlach, H. Alexander and W. Weiss: J. Non-Cryst. Solids, 117-118 (1990), 816.

32) P. S. Grant, B. Cantor and L. Katgerman: Acta Metall. Mater, 41 (1993), 3097. 